\title{
Review of Fat and Fatty Acid Requirements and Criteria for Developing Dietary Guidelines
}

\author{
Liesbeth A. Smit ${ }^{a}$ Dariush Mozaffarian ${ }^{a-c}$ Walter Willett ${ }^{a, c}$ \\ ${ }^{a}$ Departments of Nutrition and Epidemiology, Harvard School of Public Health, and ${ }^{b}$ Division of \\ Cardiovascular Medicine and ${ }^{\mathrm{C} C h a n n i n g ~ L a b o r a t o r y, ~ D e p a r t m e n t ~ o f ~ M e d i c i n e, ~ B r i g h a m ~ a n d ~ W o m e n ' s ~ H o s p i t a l ~}$ \\ and Harvard Medical School, Boston, Mass., USA
}

\section{Introduction}

In 1993 the Food and Agriculture Organization of the United Nations (FAO) and the World Health Organization (WHO) held an Expert Consultation meeting to review the scientific data on optimal consumption of dietary fats and fatty acids and to provide internationally valid recommendations. The report of this consultation was published in 1994 [FAO, 1994]. Since that time, numerous population-based observational studies and controlled trials have continued to clarify the effects of dietary fats on health outcomes. Additionally, changes in lifestyle habits have increased the incidence of several chronic diseases that significantly impact the health status of populations. To review this new scientific evidence and update the international dietary fat and fatty acid guidelines accordingly, the FAO/WHO has organized a second Expert Consultation on Fats and Fatty Acids in Human Nutrition.

As background to this second Expert Consultation, this present background document has been solicited by the $\mathrm{FAO} / \mathrm{WHO}$ to (1) provide an overview of newer dietary guidelines for fats and fatty acids established by other national and international organizations since 1994, (2) review the reported criteria and types of evidence used in establishing these other guidelines, (3) identify specific recommendations from the $1994 \mathrm{FAO} /$ WHO report that are in need of updates, and (4) assess the most appropriate criterion, types of evidence and discuss the types of dietary reference intakes (DRIs) for establishing dietary fat and fatty acid requirements to achieve health in particular populations.

\section{Overview and Comparisons of National and International Dietary Recommendations}

Reports from the United States [Food and Nutrition Board, Institute of Medicine, IOM, 2005], The Netherlands [Health Council of the Netherlands, 2001], Australia and New Zealand [National Health and Medical Research Council, 2003], German-speaking countries [2000], India [Indian Council of Medical Research, National Institute of Nutrition, 1998] and China [2008] have been included in this report. In particular, the dietary recommendations for fats and fatty acids within these reports and the $1994 \mathrm{FAO} / \mathrm{WHO}$ report are reviewed.

\section{Overview of Prior Criteria and Evidence}

The choice of the criterion or functional outcome (indicator of adequacy) that is used to determine the recommended intake for fat and fatty acids is crucial. Depending on the criterion, recommended levels of intake may differ. For example, the level of $n-3$ intake necessary for prevention of deficiencies is lower than the level of intake that minimizes the risk of coronary heart disease (CHD). The 'Appendix' contains a summary of the stated criteria provided by the dietary guideline reports, and includes the types of evidence (study designs) used to estimate associations between fat or fatty acid intake and the indicator of adequacy (criterion).

\begin{tabular}{|c|c|}
\hline ARGER & $\begin{array}{l}\text { (C) } 2009 \text { S. Karger AG, Basel and FAO } \\
0250-6807 / 09 / 0553-0044 \$ 26.00 / 0\end{array}$ \\
\hline $\begin{array}{l}\text { Fax +4161306 } 1234 \\
\text { E-Mail karger@karger.ch } \\
\text { www.karger.com }\end{array}$ & $\begin{array}{l}\text { Accessible online at: } \\
\text { www.karger.com/anm }\end{array}$ \\
\hline
\end{tabular}




\section{FAO/WHO Recommendations Are in Need of Updating}

The FAO/WHO report was published in 1994 [FAO, 1994]. Since that time, considerable new evidence has become available on associations between fats and fatty acids and disease. Based on this large body of new evidence, dietary recommendations for total fat, saturated fatty acid, polyunsaturated fatty acid and trans fatty acid intakes should be re-evaluated. Some of the new evidence of the more recent and comprehensive studies on major dietary fatty acids and chronic disease outcomes is briefly summarized below.

\section{Total Fat}

The $1994 \mathrm{FAO} / \mathrm{WHO}$ report concluded that excessive dietary fat consumption increased the risk of obesity, $\mathrm{CHD}$, and certain types of cancer.

Several recent reports of carefully performed prospective observational studies found no or small associations between total dietary fat intake and obesity, weight gain, CHD, and cancer [Hu et al., 1997; He et al., 2003; KohBanerjee et al., 2003; Xu et al., 2006; Field et al., 2007]. Other reviews have reached similar conclusions regarding the absence of a relationship between total fat consumption and cancer risk [Kushi and Giovannucci, 2002; Beresford et al., 2006; Howard et al., 2006; Prentice et al., 2006; WCRF/AICR, 2007].

Several randomized controlled trials (RCTs) of physiological measures have not found evidence for beneficial effects of low-fat diets. For example, a low-fat high-carbohydrate diet did not favorably affect serum lipids, fasting serum glucose, fasting serum insulin, or blood pressure, compared with higher fat diets [Appel et al., 2005; Schaefer et al. 2005; Gardner et al., 2007]. In a meta-analysis of clinical trials comparing low-fat $(<30 \%$ of energy from fat) energy-restricted diets to low-carbohydrate $(<60$ g/day), non-energy-restricted diets, the low-fat diets induced larger reductions in LDL-cholesterol (LDL-C), but did not improve weight loss after 12 months and they increased triglyceride and lowered HDL-cholesterol (HDL-C) levels [Nordmann, 2006].

Consistent associations have been found between higher intakes of specific dietary fats, including particular polyunsaturated fatty acids, and between substituting (easily digested) carbohydrates with polyunsaturated fat, and lower risk of heart disease [Hu, Manson and Willett et al., 2001; Mozaffarian and Willett, 2007]. Op- timal intakes of these different fatty acids may be compromised when energy percentage of total fat intake is very low.

\section{Saturated Fatty Acids}

The $1994 \mathrm{FAO} / \mathrm{WHO}$ report recommended a saturated fat intake $<10 \%$ of energy for adults.

The most often cited criteria for saturated fat recommendations are effects on one physiological measure of cardiovascular disease (CVD) risk, namely LDL-C. Saturated fats increase LDL-C, but also increase HDL-C and decrease triglyceride levels, resulting in little net effect on total cholesterol:HDL-C compared with carbohydrates [Mensink et al., 2003].

Studies suggesting adverse effects of saturated fat on heart disease often use polyunsaturated fatty acids or whole grains and fruits and vegetables as replacements for saturated fat [Mann, 2002]. In contrast, exchanging easily digested carbohydrates for saturated fat (such as in a low-fat diet) would have little predicted net benefit on serum lipids and lipoproteins for reducing risk of CVD, because this would lower HDL proportionally as much as it lowers LDL, and also raises triglycerides [Sacks and Katan, 2002]. Therefore, limits on saturated fat intake should be considered in the specific context of the replacement nutrient, as replacement with carbohydrates (particularly easily digestible carbohydrates) may have little benefit.

\section{Monounsaturated Fatty Acids}

Although monounsaturated fatty acids have not been studied as much as other fatty acids, some trials of physiological measures suggest that consumption of monounsaturated fatty acids has potential benefits on blood lipid profile and CVD risk factors [Mensink and Katan, 1992; Kris-Etherton et al., 1999; Mensink et al., 2003; Appel et al., 2005]. However, in prospective observational studies of clinical events null associations and indications of higher risks of CVD have been observed as well [Oh et al., 2005; Jakobsen et al., 2009].

Overall, it is unclear whether sufficient new evidence exists to re-evaluate the (lack of) specific dietary recommendations for monounsaturated fat intake. 


\section{Polyunsaturated Fatty Acids}

The $1994 \mathrm{FAO} / \mathrm{WHO}$ report did not suggest nutrient intake values for total, $n-6$, or $n-3$ polyunsaturated fatty acids, but focused on the ratio of linoleic acid (LA) to $\alpha$-linolenic acid (ALA) in the diet.

LA is an essential n-6 fatty acid that favorably affects the blood lipid profile, and is associated with a lower risk of CHD events and reduced risk of type 2 diabetes [Sacks and Katan, 2002; Willett, 2007; Harris et al., in press].

ALA consumption is suggested to probably, although not definitively, reduce CHD risk [Albert et al., 2005; Mozaffarian, 2005]. Although clinical benefits have not been observed across all studies, several new experimental and prospective observational studies support the view that ALA consumption reduces the incidence of CHD.

Eicosapentaenoic acid (EPA) and docosahexaenoic acid (DHA) consumption have demonstrated physiological benefits on blood pressure, heart rate, triglycerides, and likely inflammation, endothelial function, and cardiac diastolic function, and consistent evidence for a reduced risk of fatal CHD and sudden cardiac death at consumption of $\sim 250 \mathrm{mg} /$ day of EPA plus DHA [Burr et al., 1989; Mozaffarian and Rimm, 2006; Yokoyama et al., 2007; GISSI-HF Investigators, 2008]. A minimum intake of $250 \mathrm{mg} /$ day of EPA and DHA, obtained from seafood consumption, has been suggested for primary prevention of CHD death [Mozaffarian and Rimm, 2006]. DHA also plays a major role in development of the brain and retina during fetal development and the first 2 years of life [Decsi and Koletzko, 2005; Cetin and Koletzko, 2008; Helland et al., 2008]. These findings support the need for recommendations for adequate intakes of preformed DHA in pregnant women, nursing women, and young children.

\section{n-6 to n-3 Ratio}

A lower ratio of $n-6$ to $n-3$ fatty acid consumption has been recommended under the assumption that higher intakes of $n-6$ fatty acids may reduce the formation of antiinflammatory mediators from $n-3$ fatty acids [Simopoulos et al., 1999; Simopoulos, 2008]. However, this hypothesis is not supported by studies in humans [Willett, 2007].

First, there is evidence that increasing LA intake does not result in increased arachidonic acid in plasma or platelet lipids, and does not increase formation of proinflammatory mediators [Adam et al., 2003]. Furthermore, both $\mathrm{n}-6$ and $\mathrm{n}-3$ fatty acids have been shown to have anti-inflammatory properties that are protective of atherogenic changes in vascular endothelial cells [De Ca- terina et al., 2000]. Additionally, a focus on dietary ratios suggests that lowering $n-6$ fatty acid intake would have the same health effects as increasing n-3 fatty acid intake. Based on both evidence and conceptual limitations, there is no compelling scientific rationale for the continued recommendation of a specific ratio of n-6 to n-3 fatty acids or LA to ALA.

\section{Trans Fatty Acids}

The $1994 \mathrm{FAO} / \mathrm{WHO}$ report did not provide recommendations for trans fatty acids, apart from practical advice to substitute liquid oils and soft fats for hard fats and to reduce intake of both saturated and trans fats. Consistent scientific evidence that emerged both before and after 1994 shows that trans fatty acid consumption has unique adverse effects on serum lipids, including increasing LDL$\mathrm{C}$, lowering HDL-C, increasing lipoprotein(a), increasing ApoB levels, and decreasing ApoA1 levels [Mensink and Katan, 1992; Katan et al., 1994; Mozaffarian et al., 2006; Mozaffarian and Clarke, in press]. A meta-analysis of prospective observational studies indicates a $24 \%$ higher risk of CHD for every $2 \%$ increase in energy from trans fatty acids [Mozaffarian and Clarke, in press].

\section{Choice of Criteria, Evidence, and Dietary Reference Intakes}

Different types of criteria (outcomes), evidence (study designs) and DRIs have been used to set fatty acid dietary guidelines, without strong consistency either within or between guideline reports (see 'Appendix'). Notably, the types of criteria and types of evidence used to set specific guidelines could not always be clearly discerned from the reports.

This chapter reviews the potential types of criteria, study designs, and DRIs that can be used to set fatty acid guidelines, including the strengths and limitations of each, to provide best appropriate evidence for setting dietary guidelines. We provide examples from the international reports to illustrate how such evidence has been used in the past.

\section{Choice of Criteria}

Potential general criteria to define dietary requirements include the following aims: 
- to prevent clinical deficiencies;

- to provide optimal health;

- to reduce the risk of developing chronic disease.

The most appropriate and practical criteria for setting most worldwide fatty acid recommendations should be to optimize health and reduce the development of common chronic diseases; such criteria would also in nearly all cases prevent clinical deficiencies. Specific chronic diseases of interest should be identified based on burdens of morbidity and early mortality in the population and on meaningful effects of dietary fatty acids on their development.

In order to remain transparent about the development of dietary requirements, care should be taken to be explicit about the types of criteria used to set each dietary recommendation.

\section{Chronic Disease Outcomes}

Examples of chronic disease outcomes used as criterion for dietary recommendations for fatty acids include $\mathrm{CHD}$, obesity, diabetes, and specific types of cancers (see 'Appendix').

The primary strength of using disease outcome as an indicator of adequacy or optimal intake is that it represents the most direct method to assess effects on health. A drawback of using disease outcome is the absence of such data for many fatty acids, specific disease endpoints, and/or populations. However, given that many such studies are available, the more relevant drawback is often the failure to consider the different strengths and limitations of different study designs and specific studies when drawing inferences from the findings.

Examples of Using Disease Outcome as Criteria

Obesity. To assess the effects of total fat intake on obesity, the reports have used evidence from animal, ecological, and cross-sectional studies, and short-term RCTs on weight loss. As described previously, the results of animal, ecological, and cross-sectional studies should be considered hypothesis-generating and are not considered reliable or sufficient evidence for setting dietary guidelines. Observational studies of diet and body weight also have particular limitations relating to underreporting of calories or recall bias. Reverse causation is also highly problematic: small changes in body weight (or perceived body shape) can readily change individuals' diets and introduce bias in diet-weight associations.

RCTs are therefore superior for assessing diet-obesity effects. However, many RCTs have been short-term and may not reflect long-term effects of the diet on weight.
Cardiovascular Disease. To assess the effects of total fat intake on CVD, the reports have used evidence from animal experiments and from retrospective case-control, ecological, and cross-sectional designs. As described previously, such designs are generally insufficient to set dietary guidelines. For example, in many rodent studies, a high-fat rat chow is compared to standard chow, but total energy is not controlled, biasing the association between total fat as percentage of energy and the outcomes. Additionally, to obtain CVD-susceptibility, animal experiments often use specific gene-knockout models, which (in addition to other species-specific differences) may greatly reduce relevance to humans.

\section{Physiological Measures}

Examples of physiological measures used as criterion to set dietary recommendations for dietary fatty acids are serum cholesterol levels, triglyceride levels, and neural integrity.

The strength of using physiological measures as indicators of adequacy is that they are quantifiable measures that can estimate disease risk before the occurrence of clinical disease and can often be assessed directly in controlled trials. The major drawback is that physiological measures are indirect measures of actual disease outcome: they reflect only certain pathways of risk and may not be valid surrogates for total effects of the dietary intervention on health, which might also be mediated by multiple other pathways.

Because physiological measures can be assessed relatively easily in controlled trials, most of the physiological criteria are based on evidence from RCTs (see 'Appendix'). Although RCTs allow direct control of diet and minimize confounding, often participants are relatively healthy and evaluated over relatively short-term time periods, limiting potential generalizability (see 'Chronic Disease Outcomes').

\section{Examples of Using Physiological Measures as \\ Criteria}

Among the most commonly used physiological criteria for setting dietary fatty acid guidelines are the effects of saturated fat intake on LDL-C (see 'Appendix'). RCTs in humans have consistently demonstrated that saturated fat consumption raises LDL-C, and higher levels of LDL$\mathrm{C}$ are a well-established risk factor for CHD. This evidence provides an excellent illustration of the strengths and limitations of using a physiological criterion. The strength is that the quantitative effects of saturated fat on LDL-C can be definitively established. However, limita- 
tions of this criterion include: (1) the lack of confirmation in RCTs that diet-induced changes in LDL-C alter CVD event rates; (2) the lack of consideration of effects of saturated fat on other pathways of risk, such as HDLC, triglycerides, or other non-lipid risk factors; (3) the possible qualitative or even quantitative differences in effects of saturated fat on some physiological risk factors (e.g. the total cholesterol:HDL-C ratio) in populations other than those tested in RCTs, which have generally enrolled younger healthier men (rather than older adults or postmenopausal women who are at highest risk). For example, whereas saturated fat intake (compared with carbohydrate) raises LDL-C, it also raises HDL-C, so the net effect on the total cholesterol:HDL-C ratio is neutral (or even unfavorable in postmenopausal women).

\section{Deficiency Symptoms and Disease}

Deficiency symptoms are most often studied in case series/reports, animal experiments, or short-term controlled feeding studies. A strength of using deficiency symptoms as a criterion is that deficiency symptoms for essential fatty acids can be clearly defined and studied in relatively small controlled trials. Drawbacks include strong ethical limitations of testing many deficiencies, which may have unacceptable long-term effects in humans. For this reason, there is little data for most nutrients concerning the level of intake at which symptoms occur. As discussed previously, an additional major drawback is the (sometimes large) difference between levels at which clinical deficiency occur versus levels that cause lowest risk of chronic diseases, such as cancer or CVD.

For instance, deficiency symptoms have been used as criteria for recommendations for essential polyunsaturated fatty acids such as LA and ALA. However, intakes that prevent deficiency symptoms or diseases do not appear to be optimal for preventing incidence of other chronic diseases. Specifically, levels of intakes that reduce chronic diseases (e.g. LA and ALA intakes to decrease risk of CVD) are much higher than those needed to prevent clinical deficiencies. Thus, using deficiency symptoms as the criterion will result in underestimates of recommended intake. In comparison, using disease outcome as the criterion to set dietary guidelines for essential fatty acids will inherently prevent clinical deficiency.

\section{Average Intakes in National Survey Studies}

For some fatty acids and age groups, insufficient data are available to use disease or physiological criteria for setting dietary guidelines. In these cases, average national intakes have been used as a criterion, when deficiencies are not present in the population. Guidelines can be set based on average intakes (e.g. median national intakes) or relative extremes of intake (e.g. the upper 10th percentile of national intake).

The strengths of this approach are that mean national intakes are relatively practical and easy to measure, and that recommendations based on average national intakes are unlikely to have large unexpected adverse consequences, given that much of the population is already at these levels. A major drawback is that such intakes may not be optimal for reducing disease risk, even though overt deficiencies are not present. For example, in populations without overt clinical deficiencies of $n-3$ fatty acids, higher intakes may nevertheless substantially reduce the risk of fatal CHD and sudden cardiac death. Such guidelines, based on average intakes in one population, may also be less appropriate for other populations or age groups.

\section{Examples of Using Average National Intake as \\ Criteria}

The Health Council of the Netherlands used the upper 10th percentile of national intake of naturally occurring trans fatty acids (i.e. trans fatty acid intake from natural sources such as meats, dairy products, eggs, and fish) to determine the recommended upper intake level of total trans fat intake, which varies between 0.7 and $1.0 \%$ of total energy in dependence upon the age group.

Because the intake of dairy products in The Netherlands is very high, this upper level of intake may be less appropriate for Asian countries, in which the intake of dairy products is much lower. Specifically, the goal of the Dutch guidelines was to limit intake of partially hydrogenated oils, but not naturally occurring trans fatty acids. If applied to an Asian country, this intake level could result in a much higher level of intake of partially hydrogenated vegetable oil than desirable.

\section{Equilibrium Maintenance}

Equilibrium maintenance describes the balance of nutrient intake and loss, as measured by factorial estimation. The factorial method involves estimating the factors that determine the requirement, such as increased requirements for growth, pregnancy, and lactation, or losses via urine or feces.

Examples of equilibrium maintenance used as criterion to set dietary recommendations are estimations of deposition and losses of LA and ALA during pregnancy and lactation (factorial methods). 
Convincing Evidence is based on epidemiological studies showing evidence consistent associations between exposure and disease, with little or no evidence to the contrary. The available evidence is based on a substantial number of studies including prospective observational studies and where relevant, randomized controlled trials of sufficient size, duration and quality showing consistent effects. The association should be biologically plausible.

Probable Evidence is base on epidemiological studies showing evidence fairly consistent associations between exposure and disease, but where there are perceived shortcomings in the available evidence or some evidence to the contrary, precluding a more definite judgment. Shortcomings in the evidence may be any of the following: insufficient duration of trials (or studies); insufficient trials (or studies) available; inadequate sample sizes; and incomplete follow-up. Laboratory evidence is usually supportive. Again, the association should be biologically plausible.

Possible Evidence is based mainly on the findings from caseevidence control and cross-sectional studies. Insufficient randomized controlled trials, observational studies or nonrandomized controlled trials are available. Evidence based on no epidemiological studies, such as clinical and laboratory investigations, is supportive. More trials are required to support the tentative associations, which should also be biologically plausible.

Insufficient Evidence is based on the findings of a few studies which evidence are suggestive, but are insufficient to establish an association between exposure and disease. Limited or no evidence is available from randomized controlled trials. More well-designed research is required to support the tentative associations.

Source: World Health Organization: Diet, Nutrition and the Prevention of Chronic Diseases. Geneva, WHO, 2003.

Fig. 1. FAO/WHO criteria used to describe the strength of evidence [WHO, 2003].

A strength of using equilibrium maintenance as an indicator of adequacy is that the factorial method measures the actual losses of a fatty acid and estimates the required intake when other data are not available. The drawback of using these measures is that individual losses of fatty acids may vary to a great extent and estimations may not apply to all individuals. The intake required to maintain equilibrium depends on the level at which equilibrium is maintained, and thus the existing level of an individual or population may not be optimal. Importantly, such criteria may also have little relevance to the incidence of disease, the main endpoint of interest.

\section{Animal Models}

In the international reports discussed here, animal models of inadequacy were not used as primary criteria

\section{NHMRC levels of evidence}

I Evidence obtained from a systematic review of all relevant randomized controlled trials

II Evidence obtained from at least one properly designed randomized controlled trial

III-1 Evidence obtained from well-designed pseudorandomized controlled trials (alternate allocation or some other method)

III-2 Evidence obtained from comparative studies (including systematic reviews of such studies) with concurrent controls and allocation not randomized, cohort studies, case-control studies, or interrupted time series with a control group

III-3 Evidence obtained from comparative studies with historical control, two or more single-arm studies, or interrupted time series without a parallel control group

IV Evidence obtained from case series, either post-test or pre-test/post-test

Source: National Health and Medical Research Council:

A guide to the development, evaluation and implementation

of clinical practice guidelines. Canberra, NHMRC, 1999.

Fig. 2. NHMRC levels of evidence [National Health and Medical Research Council, 2003].

to set dietary recommendations for fats and fatty acids. However, animal experiments that evaluated disease outcome or physiological measures have been used as supporting evidence for recommendations.

Animal studies are powerful for doing basic research and generating hypotheses, but the major limitations in generalizability to humans makes such evidence insufficient to set dietary recommendations.

\section{Choosing the Type of Evidence}

Types of evidence generally used to establish dietary requirements have included the following:

- animal studies;

- ecological studies, prevalence studies;

- retrospective case-control studies of disease outcomes;

- RCTs of physiological measures;

- prospective cohort studies of disease outcomes;

- RCTs of disease outcomes.

Compared to information available about criteria and DRI, often discussion of the choice of evidence is missing in reports addressing dietary guidelines. Both the 


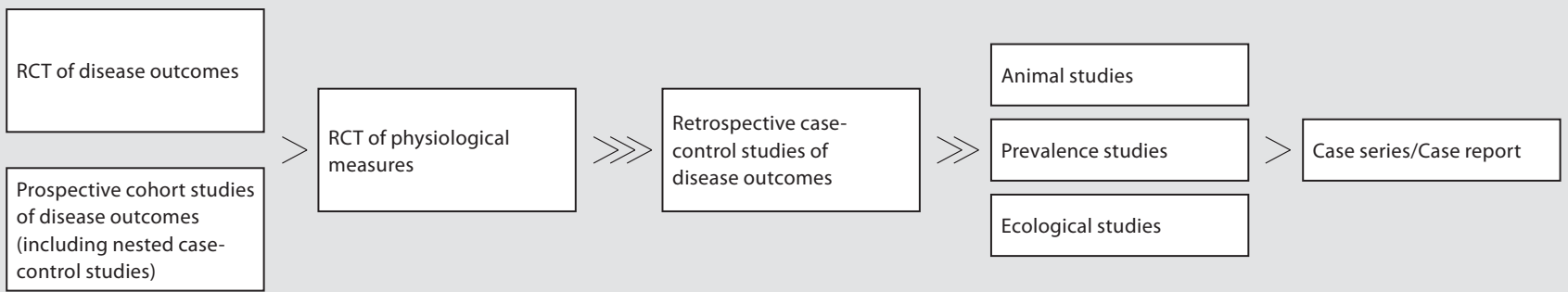

Fig. 3. Ranking of validity of types of evidence for setting dietary fatty acid requirements.

National Health and Medical Research Council (NHMRC) and the WHO have issued useful rankings of the criteria describing the strength of evidence (fig. 1, 2). However, these rankings of evidence do not provide clear guidelines for setting dietary guidelines, but rather discuss the general strength of evidence.

In this report, we propose a ranking system for evidence from studies that can be considered as a guideline to determine whether current data is sufficient to evaluate human requirements and set dietary recommendations (fig. 3), assuming of course that the study is well conducted. Optimally, evidence for setting dietary fatty acid requirements would be derived from concordant evidence from well-conducted RCTs of incidence of disease outcomes, prospective cohort studies of incidence of disease outcomes (including nested case-control studies), and RCTs of physiological measures, supported by findings from retrospective case-control studies, ecological studies, and animal experiments. For many fats and fatty acids, well-conducted and adequately powered RCTs of disease outcomes are not available, especially for chronic diseases. When such evidence is not available, concordant evidence from well-conducted prospective cohort studies of disease outcomes and RCTs of physiological measures are often sufficient to set dietary recommendations. Evidence from only RCTs of physiological measures without additional concordant evidence from controlled trials or prospective cohort studies of disease outcomes, or from only retrospective case-control studies, ecological or cross-sectional studies, or animal experiments may be insufficient to set dietary recommendations, especially for chronic diseases. When evaluating studies as evidence for setting dietary recommendations, these strengths and limitations of each study design should be critically evaluated.
The major strength of properly executed RCTs is the minimization of confounding, but many other study design limitations can be present and limit the utility of the results. Prospective cohort studies have many strengths, but the major potential limitation is the inability to definitively exclude residual confounding. A review of these strengths and limitations demonstrates the strong complementary nature of the strengths and limitations of RCTs versus prospective cohorts. When RCTs of disease outcomes are not available, RCTs of physiological measures (intermediate endpoints or risk factors for disease) can provide concordant evidence for the effects on disease risk.

Retrospective case-control studies are efficient for evaluating rare diseases, but the limitations of recall bias, selection bias, and inability to include fatal cases render them suboptimal for studying other disease endpoints. Because dietary guidelines for the population should not be determined based on rare diseases, retrospective casecontrol studies are useful for generating hypotheses, but are usually insufficient for setting dietary guidelines.

Ecological, cross-sectional, or prevalence studies are very useful in providing an initial hypothesis that can be further tested in prospective cohort studies and clinical trials, but design limitations for assessing causality are too strong for such data to be sufficient for determining dietary recommendations.

Animal experiments are powerful study designs for evaluating mechanisms, assessing pathways, and providing concordant evidence to findings of human studies, but by themselves are insufficient to set dietary recommendations for fats and fatty acids in humans.

Case series or reports describe the manifestation, the course, or the prognosis of a condition. Due to lack of comparability, this type of evidence is generally insufficient for setting dietary recommendations, except perhaps for deficiency symptoms that are manifested in specific populations or during historical incidents. 
Table 1. Dietary recommendations for fats and fatty acids

\begin{tabular}{|c|c|c|}
\hline & FAO/WHO & Recent reports \\
\hline Total fat & $\begin{array}{l}15-30 / 35 \% \text { of energy depending on } \\
\text { energy balance }\end{array}$ & ranging from 20 to $40 \%$ of energy \\
\hline Saturated fat & upper limit of $10 \%$ of energy & $\begin{array}{l}\text { consistent with } \mathrm{FAO} / \mathrm{WHO} \text {, or intakes as low } \\
\text { as possible }\end{array}$ \\
\hline Monounsaturated fatty acids & none & none or $10 \%$ of energy \\
\hline $\begin{array}{l}\text { n-6 Polyunsaturated fatty acids } \\
\text { (LA) }\end{array}$ & $4-10 \%$ of energy & ranging from 2 to $10 \%$ of energy \\
\hline \multicolumn{3}{|l|}{ n-3 Polyunsaturated fatty acids } \\
\hline ALA & none & ranging from 0.5 to $2 \%$ of energy \\
\hline EPA and DHA & none & $\begin{array}{l}90-650 \mathrm{mg} / \text { day for EPA + DHA, } \\
\text { and values ranging from } 40 \text { to } 3,000 \mathrm{mg} / \text { day } \\
\text { for different age groups }\end{array}$ \\
\hline Cholesterol & $300 \mathrm{mg} /$ day of dietary cholesterol & $\begin{array}{l}300 \mathrm{mg} / \text { day of dietary cholesterol, or intake as } \\
\text { low as possible }\end{array}$ \\
\hline $\begin{array}{l}\text { Substances associated with fats and } \\
\text { oils }\end{array}$ & $\begin{array}{l}0.6 \mathrm{mg} \text { tocopherol (vitamin } \mathrm{E}) \\
\text { equivalents per gram of foods high } \\
\text { in polyunsaturated fat }\end{array}$ & $\begin{array}{l}\text { none or } 0.4 \mathrm{mg} \text { tocopherol equivalent per } \\
\text { gram of diene fatty acid equivalent }\end{array}$ \\
\hline
\end{tabular}

Table 2. Types of DRI

Definition and description

Intake that meets the nutrient needs of half of the healthy individuals in a life stage or gender group.

Reflects the estimated average (median) requirement and is particularly appropriate for applications related to planning and assessing intakes for groups of persons.

Recommended dietary A value based on observed or experimentally determined allowance (RDA) estimates of nutrient intake by a group of people who are apparently healthy and assumed to be maintaining an adequate nutritional state.

The RDA is calculated from the EAR and covers the requirements for $97-98 \%$ of the population. It is dependent upon estimating the variance around the EAR and reflects a point estimate defined as 2 standard deviations above the EAR.
Historic use for fats and fatty acids

Not traditionally used for fats and fatty acids.

Not traditionally used for fats and fatty acids.
Tolerable upper intake level Highest average intake that is likely to pose no risk. (UL)

Adequate intake (AI)

Used when an EAR/RDA cannot be developed; average intake level based on observed or experimental intakes.

Acceptable macronutrient An intake range for an energy source associated with reduced distribution range (AMDR) risk of chronic disease.
Has been used for total fat, saturated fat, total polyunsaturated fat, ALA, $\mathrm{EPA}+\mathrm{DHA}$, and dietary cholesterol.

Has been used for total fat, LA, ALA, and EPA + DHA.

Has been used for total fat, LA, and ALA. 


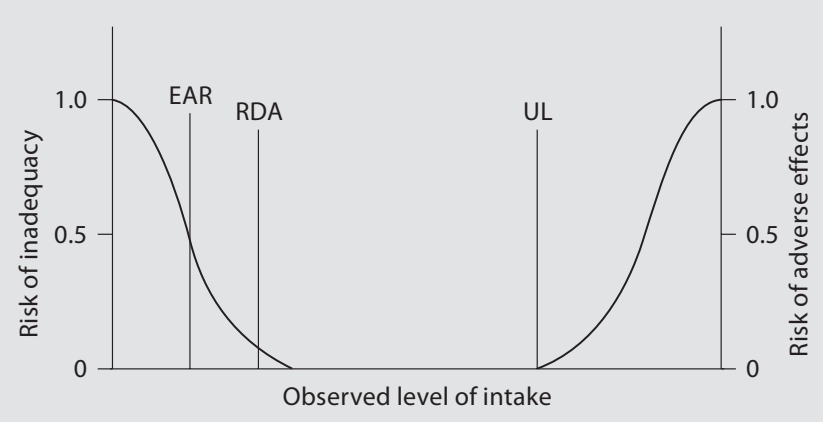

Fig. 4. Dietary reference intake distribution [Institute of Medicine, 2005].

This approach of ranking the validity of study designs based on the strengths and limitations of each study design allows for clear and explicit criteria, but does not take into account whether the data is available for each fatty acid and disease outcome. For some associations, availability of data or studies may be less than optimal, for example between nutrition and cancer. In such cases, dietary fatty acid requirements can be considered, but will require careful consideration of available data and, most importantly, be transparent about the approach and the strength of evidence used to set the dietary requirements.

The Framework for DRI Development background paper by Taylor [2008] suggests that even in the face of limited data, scientific judgment can be important. It advocates that science-based judgment is more useful than no recommendation at all. In that light, it might be useful to look at data not meeting the suggested optimal criteria for setting dietary fatty acid requirements (described previously), e.g. when RCTs and prospective cohort studies of incidence of disease outcomes are not possible or available. In some limited cases, scientific judgment may be necessary to offer a reference value when only limited data is available (e.g. only ecological and animal studies), but action is necessary and there is insufficient time to wait for more data. In these cases, a 'portfolio' or 'mosaic' approach - in which all available types of studies, the biological plausibility, and data consistency (taking weight of study design into account) are considered - may be a useful approach when the linear approach based solely on study design described previously is not suitable.

On the other hand, it must be remembered that reliance on scientific judgment, in the absence of optimal data, can lead to subjective and erroneous conclusions that can result in unhelpful or even harmful health consequences.
In order to remain transparent about the development of dietary requirements, care should be taken to be explicit about the type of evidence used, particularly when according to the ranking above it may be considered suboptimal.

\section{Choice of DRI}

Historically, nutrient reference values - more recently termed DRIs - were developed to address acute or subacute clinical deficiencies of vitamins, minerals, protein, and energy (calories). More recently, the use of DRIs has been expanded to include other substances in foods, such as fats and fatty acids, and to address chronic diseases. Several different types of DRIs exist (table 2; fig. 4).

When applied to fatty acids, DRIs have been used inconsistently among different countries/institutions. For example, in the US and Canadian guidelines, acceptable macronutrient distribution ranges (AMDRs) refer to appropriate ranges of usual intakes of individuals, while in the $\mathrm{FAO} / \mathrm{WHO}$ report an AMDR refers to a population mean intake goal [King, 2007]. In our review, the inconsistent use of DRIs is obvious from the data presented in the 'Appendix'. For instance, the IOM reported an AMDR for total fat in adults, but adequate intakes (AI) for total fat intake among infants; Eurodiet used population goals to set DRIs; and the FAO/WHO report used only a tolerable upper intake level (UL) for total fat intake.

Similarly, for LA, several reports used AIs, based on prevention of deficiency, or even ULs. Use of AIs or ULs for LA would prevent higher intakes that may decrease the risk of chronic disease. For LA, as well as total fat, AMDRs might be more appropriate.

Thus, whereas DRIs were developed with a focus on preventing deficiencies, their application to many fatty acid recommendations must be considered in the context of reducing risk of chronic disease, which may not be adequately captured in DRIs. As discussed in Using Criteria to Establish Nutrient Intake Values (NIVs) by Yates [2007], it is also possible to have multiple average nutrient requirements corresponding to different criteria, and have public health policy planners determine which level is appropriate for the population of interest.

For some fatty acids, such as trans fatty acids, there is no known level of inadequacy and even small incremental intakes of these fatty acids are associated with risk of chronic disease. Therefore traditional DRIs, such as estimated average requirements (EAR) and recommended dietary allowances (RDAs), are not adequately relevant 
to the health effects of these fatty acids. As shown in figure 4, the EAR and RDA are based on a U-shaped association between intake of the nutrient and adverse effects (either inadequacy or other adverse effects). For fatty acids, for which there is no risk of inadequacy, neither EAR nor RDA are appropriate. ULs may also be problematic. For example, in the IOM [2005] report on DRIs: 'A UL is not set for trans fatty acids because any incremental increase in trans fatty acid intake increases CHD risk.' The UL is defined by a level at which intake does not pose a risk, which is not the case for trans fatty acids.

\section{Conclusion}

Since the 1994 FAO/WHO report, new studies have become available that provide further insight into the effects of many types of fats and fatty acids on disease outcomes. Evidence from these studies has been used to set new dietary recommendations that have been published in more recent national and international reports. However, the use of criteria and types of evidence has been inconsistent. Some types of evidence are more likely to be appropriate for determining dietary fatty acid guidelines than others. Optimal evidence for setting dietary fatty acid requirements is taken from well-conducted randomized controlled trials of incidence of disease outcomes, prospective cohort studies of incidence of disease outcomes (including nested case-control studies), and randomized controlled trials of physiological measures.

In the light of new evidence for associations between low intakes of some unsaturated fatty acids and increased risk of chronic disease, and the increasing burden of these diseases on populations, optimal criteria are those that attend to optimal health and reduce the risk of developing chronic disease. In most cases this will also prevent clinical deficiencies of the essential fatty acids. Regardless of the criteria or type of evidence chosen, the process in which dietary requirements are established should be transparent.

\section{Disclosure Statement}

Ms. Smit has nothing to disclose. Dr. Mozaffarian has received research grants from GlaxoSmithKline, Sigma Tau, and Pronova for an investigator-initiated trial of fish oil to prevent post-surgical arrhythmia. During the last 15 years, Dr. Willett has given many talks and written editorials about the adverse effect of trans fat and benefits of non-hydrogenated unsaturated fat.

\section{Appendix}

Summarized overview of stated criteria and evidence used to determine dietary guidelines for fatty acids (based on adverse effects on outcome, unless otherwise stated)

\begin{tabular}{|c|c|c|c|}
\hline & Disease outcome & Physiological measure & Average intake \\
\hline \multirow[t]{11}{*}{ Total fat } & $\mathrm{CVD}, \mathrm{RCT}^{5,6, \mathrm{~b}}, \mathrm{CO}^{6, \mathrm{~b}}, \mathrm{EC}^{1}$ & $\begin{array}{l}\text { LDL-C EC }{ }^{1}, \mathrm{RCT}^{7} \\
\text { HDL-C, RCT }\end{array}$ & \multirow{11}{*}{$\begin{array}{l}\text { Average intake from } \\
\text { human milk (infants) } \\
\text { Gradual decrease of } \\
\text { fat intake compared } \\
\text { with human milk } \\
\text { (infants 6-12 months) }^{4}\end{array}$} \\
\hline & Increased obesity, $\mathrm{RCT}^{7}$, a $, \mathrm{A}^{1}, \mathrm{EC}^{3}, ?^{5}$ & Triglycerides $\mathrm{NS}^{4}$ & \\
\hline & No effect on obesity, $\mathrm{CS}^{7}$ & Dyslipoproteinemia and atherosclerosis, $E ?^{5}, \mathrm{O} ?^{5}$ & \\
\hline & & $\begin{array}{l}\text { Postprandial lipids and blood coagulation factor VII } \\
\text { concentration (used to set upper limit) }{ }^{\mathrm{b}}, \mathrm{RCT}^{4}\end{array}$ & \\
\hline & Colon cancer, $\mathrm{EC}^{1}, \mathrm{CC}^{1} \mathrm{~A}^{1}$, conference & \multirow{7}{*}{$\begin{array}{l}\text { Favorable effects on: } \\
\text { Triglycerides and HDL-C (used to set lower limit) }{ }^{\mathrm{b}}, \mathrm{RCT}^{4} \\
\text { Responses in postprandial glucose and insulin concentrations } \mathrm{RCT}^{6}, \mathrm{CO}^{6}\end{array}$} & \\
\hline & review ${ }^{5}$, (not according to $\mathrm{CO}^{1}$ ) & & \\
\hline & Breast cancer, $\mathrm{EC}^{1}$ & & \\
\hline & Prostate cancer, $\mathrm{CC}^{1}$ & & \\
\hline & Diabetes, $\mathrm{O} ?^{6}, \mathrm{E} ?^{6}$ & & \\
\hline & $\begin{array}{l}\text { Favorable effects on: } \\
\text { Stroke } C^{1} A^{1} E C^{1}\end{array}$ & & \\
\hline & & & \\
\hline \multirow[t]{3}{*}{ Saturated fat } & $\mathrm{CVD}, \mathrm{CO}^{7}$ & $\begin{array}{l}\text { Serum total cholesterol, } \mathrm{LDL}^{\mathrm{C}}, \mathrm{RCT}^{1,6,7}, \mathrm{CO}^{6,7}, \mathrm{EC}^{1} \\
\text { Serum triglycerides } \mathrm{NS}^{5}\end{array}$ & \multirow{3}{*}{$\begin{array}{l}\text { Upper 10th percentile of } \\
\text { national intake } \\
\text { Average intake from } \\
\text { human milk (infants) }\end{array}$} \\
\hline & & Ratio total cholesterol: HDL-C, RCT ${ }^{4}$ & \\
\hline & & & \\
\hline \multirow{2}{*}{$\begin{array}{l}\text { Monounsaturated } \\
\text { fatty acids }\end{array}$} & - & Favorable effects on: & \multirow[t]{2}{*}{-} \\
\hline & & Serum total cholesterol RCT ${ }^{1}$ & \\
\hline \multirow{5}{*}{$\begin{array}{l}\text { Polyunsaturated } \\
\text { fatty acids }\end{array}$} & Cancer, $\mathrm{CO}^{4}$ & Favorable effects on: & \multirow[t]{5}{*}{-} \\
\hline & & Serum total cholesterol $\mathrm{RCT}^{1}$ & \\
\hline & Favorable effects on: & Equilibrium maintenance $(E)$ : & \\
\hline & $\mathrm{CHD}, \mathrm{CO}^{4}$ & $\begin{array}{l}\text { Deposition of essential fatty acids in growing tissue } \\
\text { of pregnant women }{ }^{1}\end{array}$ & \\
\hline & & Composition of milk in omnivorous lactating women ${ }^{1}$ & \\
\hline
\end{tabular}

Fat and Fatty Acid Requirements in 


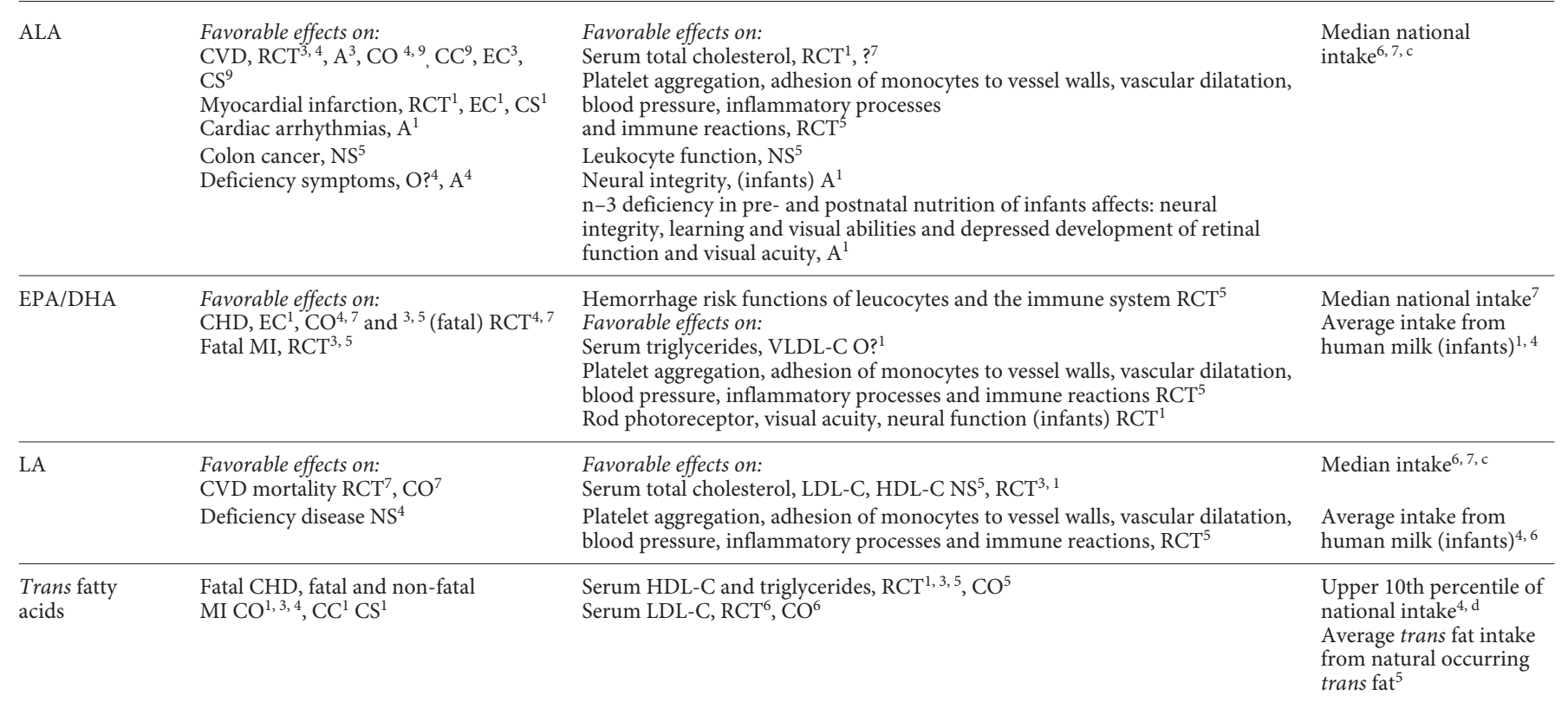

Cholesterol

Serum total cholesterol, $\mathrm{RCT}^{5,1}, \mathrm{NS}^{6}$

Dietary Guidelines Report: ${ }^{1}$ FAO/WHO [1994]; ${ }^{2}$ India [1998]; ${ }^{3}$ Eurodiet [2000]; ${ }^{4}$ The Netherlands [2001]; ${ }^{5}$ DACH [2000]; ${ }^{6}$ United States/Canada [IOM, 2005]; $;{ }^{7}$ Australia /New Zealand [2003]; ${ }^{8}$ China [2008]; ${ }^{9}$ ISSFAL [2004].

Study Design of Provided Evidence: NS = Not specified.

Experimental Studies: E? = Not further specified; RCT = randomized controlled clinical trial; $\mathrm{A}=$ animal study.

Observational Studies: $\mathrm{O} ?=$ Not further specified; $\mathrm{CO}=$ cohort study; $\mathrm{CC}=$ case-control study; EC = ecologic study; CS = cross-sectional (prevalence) study.

a The association between total fat intake and obesity is based on the high energy density of fat. Energy density contributes to a higher intake of energy (a risk factor for obesity) and fat content is closely linked to energy density in the Australian diet [AU/NZ, 2003]. No evidence for a direct causal effect between fat in take as percent of energy and obesity is provided by the NHMRC. ${ }^{b}$ The association between total fat and serum cholesterol and risk of CVD, is noted because high fat intake is associated with saturated fat intake, not because of a direct effect of high fat diets on risk of CHD. ${ }^{\mathrm{c}}$ Based on the highest median intakes of the gender-related age group taken from an analysis of the National Nutrition Survey of Australia. ${ }^{\mathrm{d}}$ Based on the 10 th percentile of intake of naturally-occurring trans fats that varies, dependent on the age group, between 0.7 and 1.0 percent of total energy.

\section{References}

Adam O, Wolfram G, Zollner N: Influence of dietary linoleic acid intake with different fat intakes on arachidonic acid concentrations in plasma and platelet lipids and eicosanoid biosynthesis in female volunteers. Ann Nutr Metab 2003;47:31-36.

- Albert CM, Oh K, Whang W, Manson JE, Chae CU, Stampfer MJ, Willett WC, Hu FB: Dietary alpha-linolenic acid intake and risk of sudden cardiac death and coronary heart disease. Circulation 2005;112:3232-3238.

-Appel LJ, Sacks FM, Carey VJ, Obarzanek E, Swain JF, Miller ER 3rd, Conlin PR, Erlinger TP, Rosner BA, Laranjo NM, Charleston J, McCarron P, Bishop LM: Effects of protein, monounsaturated fat, and carbohydrate intake on blood pressure and serum lipids: results of the OmniHeart randomized trial. JAMA 2005;294:2455-2464.

Beresford SA, Johnson KC, Ritenbaugh C, Lasser NL, Snetselaar LG, Black HR, Anderson GL, Assaf AR, Bassford T, Bowen D, Brunner RL, Brzyski RG, Caan B, Chlebowski RT, Gass M, Harrigan RC, Hays J, Heber D, Heiss G, Hendrix SL, Howard BV, Hsia J, Hubbell FA, Jackson RD, Kotchen JM, Kuller LH, LaCroix AZ,
Lane DS, Langer RD, Lewis CE, Manson JE, Margolis KL, Mossavar-Rahmani Y, Ockene JK, Parker LM, Perri MG, Phillips L, Prentice RL, Robbins J, Rossouw JE, Sarto GE, Stefanick ML, Van Horn L, Vitolins MZ, Wactawski-Wende J, Wallace RB, Whitlock E: Low-fat dietary pattern and risk of colorectal cancer: the Women's Health Initiative Randomized Controlled Dietary Modification Trial. JAMA 2006;295:643-654.

Burr ML, Fehily AM, Gilbert JF, Rogers S, Holliday RM, Sweetnam PM, Elwood PC, Deadman NM: Effects of changes in fat, fish, and fibre intakes on death and myocardial reinfarction: diet and reinfarction trial (DART). Lancet 1989;2:757-761.

Cetin I, Koletzko B: Long-chain omega-3 fatty acid supply in pregnancy and lactation. Curr Opin Clin Nutr Metab Care 2008;11:297302.

Chinese Nutrition Society: Dietary Guidelines for the Chinese Population. China, Tibet People's Publishing House, 2008.

De Caterina R, Liao JK, Libby P: Fatty acid modulation of endothelial activation. Am J Clin Nutr 2000;71:213S-223S.
Decsi T, Koletzko B: n-3 fatty acids and pregnancy outcomes. Curr Opin Clin Nutr Metab Care 2005;8:161-166.

Deutsche Gesellschaft für Ernährung: Die Referenzwerte für die Nährstoffzufuhr. Neustadt an der Weinstrasse, Umschau, 2008.

Eurodiet: Eurodiet core report: European dietary guidelines. 2000. http://eurodiet.med. uoc.gr/eurodietcorereport.pdf (accessed 1 October 2008).

FAO: Fats and Oils in Human Nutrition: Report of a Joint FAO/WHO Expert Consultation. Rome, FAO, 1994.

Field AE, Willett WC, Lissner L, Colditz GA: Dietary fat and weight gain among women in the Nurses' Health Study. Obesity (Silver Spring) 2007;15:967-976.

- Gardner CD, Kiazand A, Alhassan S, Kim S, Stafford RS, Balise RR, Kraemer HC, King AC: Comparison of the Atkins, Zone, Ornish, and LEARN diets for change in weight and related risk factors among overweight premenopausal women: the A TO Z Weight Loss Study: a randomized trial. JAMA 2007; 297:969-977. 
-GISSI-HF Investigators; Tavazzi L, Maggioni AP, Marchioli R, Barlera S, Franzosi MG, Latini R, Lucci D, Nicolosi GL, Porcu M, Tognoni G: Effect of $n-3$ polyunsaturated fatty acids in patients with chronic heart failure (the GISSI-HF trial): a randomised, doubleblind, placebo-controlled trial. Lancet 2008; 372:1223-1230.

Harris WS, Mozaffarian D, Rimm E, Kris-Etherton P, Rudel LL, Appel LJ, Engler MM, Engler MB, Sacks F: Omega- 6 Fatty Acids and Risk for Cardiovascular Disease. A Science Advisory from the American Heart Association Nutrition Committee. In press.

- He K, Merchant A, Rimm EB, Rosner BA, Stampfer MJ, Willett WC, Ascherio A: Dietary fat intake and risk of stroke in male US healthcare professionals: 14 year prospective cohort study. BMJ 2003;327:777-782.

Health Council of the Netherlands: Dietary reference intakes: energy, proteins, fats, and digestible carbohydrates. The Hague, Health Council of the Netherlands, 2001.

-Helland IB, Smith L, Blomen B, Saarem K, Saugstad OD, Drevon CA: Effect of supplementing pregnant and lactating mothers with $n-3$ very-long-chain fatty acids on children's IQ and body mass index at 7 years of age. Pediatrics 2008;122:e472-e479.

- Howard BV, Manson JE, Stefanick ML, Beresford SA, Frank G, Jones B, Rodabough RJ, Snetselaar L, Thomson C, Tinker L, Vitolins M, Prentice R: Low-fat dietary pattern and weight change over 7 years: the Women's Health Initiative Dietary Modification Trial. JAMA 2006;295:39-49.

- Hu FB, Stampfer MJ, Manson JE, Rimm E, Colditz GA, Rosner BA, Hennekens CH, Willett WC: Dietary fat intake and the risk of coronary heart disease in women. $\mathrm{N}$ Engl J Med 1997;337:1491-1499.

Hu FB, Manson JE, Willett WC: Types of dietary fat and risk of coronary heart disease: a critical review. J Am Coll Nutr 2001;20:5-19.

Indian Council of Medical Research: Dietary guidelines for Indians - A Manual. New Delhi, ICMR, 1998.

Institute of Medicine: Dietary Reference Intakes for Energy, Carbohydrate, Fiber, Fat, Fatty Acids, Cholesterol, Protein, and Amino Acids (Macronutrients). Washington, National Academies, 2005.

International Society for the Study of Fatty Acids and Lipids: Recommendations for Dietary Intake of Polyunsaturated Fatty Acids in Healthy Adults. ISSFAL, 2004.

-Jakobsen MU, O’Reilly EJ, Heitmann BL, Pereira MA, Bälter K, Fraser GE, Goldbourt U, Hallmans G, Knekt P, Liu S, Pietinen P, Spiegelman D, Stevens J, Virtamo J, Willett WC, Ascherio A: Major types of dietary fat and risk of coronary heart disease: a pooled analysis of 11 cohort studies. Am J Clin Nutr 2009;89:1425-1432.

Katan MB, Zock PL, Mensink RP: Effects of fats and fatty acids on blood lipids in humans: an overview. Am J Clin Nutr 1994;60:1017S1022 S.
King J, Vorster H, Tome D: Nutrient intake values (NIVs): a recommended terminology and framework for the derivation of values. Food Nutr Bull 2007;28(suppl):S16-S26.

Koh-Banerjee P, Chu NF, Spiegelman D, Rosner B, Colditz G, Willett W, Rimm E: Prospective study of the association of changes in dietary intake, physical activity, alcohol consumption, and smoking with 9-y gain in waist circumference among 16587 US men. Am J Clin Nutr 2003;78:719-727.

Kris-Etherton PM, Pearson TA, Wan Y, Hargrove RL, Moriarty K, Fishell V, Etherton TD: High-monounsaturated fatty acid diets lower both plasma cholesterol and triacylglycerol concentrations. Am J Clin Nutr 1999;70:1009-1015.

Kushi L, Giovannucci E: Dietary fat and cancer. Am J Med 2002;113(suppl 9B):63S-70S.

Mann JI: Diet and risk of coronary heart disease and type 2 diabetes. Lancet 2002;360:783-789.

Mensink RP, Katan MB: Effect of dietary fatty acids on serum lipids and lipoproteins: a meta-analysis of 27 trials. Arterioscler Thromb 1992;12:911-919.

Mensink RP, Zock PL, Kester AD, Katan MB: Effects of dietary fatty acids and carbohydrates on the ratio of serum total to HDL cholesterol and on serum lipids and apolipoproteins: a meta-analysis of 60 controlled trials. Am J Clin Nutr 2003;77:1146-1155.

Mozaffarian D: Does alpha-linolenic acid intake reduce the risk of coronary heart disease? A review of the evidence. Altern Ther Health Med 2005;11:24-30, quiz 31, 79.

Mozaffarian D, Katan MB, Ascherio A, Stampfer MJ, Willett WC: Trans fatty acids and cardiovascular disease. N Engl J Med 2006;354: 1601-1613.

Mozaffarian D, Rimm EB: Fish intake, contaminants, and human health: evaluating the risks and the benefits. JAMA 2006;296:1885-1899.

Mozaffarian D, Willett WC: Trans fatty acids and cardiovascular risk: a unique cardiometabolic imprint? Curr Atheroscler Rep 2007;9:486-493.

Mozaffarian D, Clarke R: Quantitative effects on cardiovascular risk factors and coronary heart disease risk of replacing partially hydrogenated vegetable oils with other fats and oils. Eur J Clin Nutr 2009;63:522-533.

National Health and Medical Council: A guide to the development, evaluation and implementation of clinical practice guidelines. Canberra, NHMRC, 1999.

National Health and Medical Council: Dietary Guidelines for Australian Adults. Canberra, NHMRC, 2003.

- Nordmann AJ, Nordmann A, Briel M, Keller U, Yancy WS Jr, Brehm BJ, Bucher HC: Effects of low-carbohydrate vs. low-fat diets on weight loss and cardiovascular risk factors: a meta-analysis of randomized controlled trials. Arch Intern Med 2006;166:285-293.

-Oh K, Hu FB, Manson JE, Stampfer MJ, Willett WC: Dietary fat intake and risk of coronary heart disease in women: 20 years of followup of the nurses' health study. Am J Epidemiol 2005;161:672-679.
Prentice RL, Caan B, Chlebowski RT, Patterson R, Kuller LH, Ockene JK, Margolis KL, Limacher MC, Manson JE, Parker LM, Paskett E, Phillips L, Robbins J, Rossouw JE, Sarto GE, Shikany JM, Stefanick ML, Thomson CA, Van Horn L, Vitolins MZ, WactawskiWende J, Wallace RB, Wassertheil-Smoller S, Whitlock E, Yano K, Adams-Campbell L, Anderson GL, Assaf AR, Beresford SA, Black HR, Brunner RL, Brzyski RG, Ford L, Gass M, Hays J, Heber D, Heiss G, Hendrix SL, Hsia J, Hubbell FA, Jackson RD, Johnson KC, Kotchen JM, LaCroix AZ, Lane DS, Langer RD, Lasser NL, Henderson MM: Low-fat dietary pattern and risk of invasive breast cancer: the Women's Health Initiative Randomized Controlled Dietary Modification Trial. JAMA 2006;295:629-642.

Sacks FM, Katan M: Randomized clinical trials on the effects of dietary fat and carbohydrate on plasma lipoproteins and cardiovascular disease. Am J Med 2002;113;(suppl 9B):13S24S.

Schaefer EJ, Gleason JA, Dansinger ML: The effects of low-fat, high-carbohydrate diets on plasma lipoproteins, weight loss, and heart disease risk reduction. Curr Atheroscler Rep 2005;7:421-427.

Simopoulos AP, Leaf A, Salem N Jr: Essentiality of and recommended dietary intakes for omega- 6 and omega-3 fatty acids. Ann Nutr Metab 1999;43:127-130.

Simopoulos AP: The importance of the omega-6/omega-3 fatty acid ratio in cardiovascular disease and other chronic diseases. Exp Biol Med (Maywood) 2008;233:674-688.

Taylor C: Framework for DRI Development. Washington, Institute of Medicine, 2008. http://www.iom.edu/Object.File/Master/ 54/358/DRI\%20Framework.pdf.

Willett WC: The role of dietary n-6 fatty acids in the prevention of cardiovascular disease. J Cardiovasc Med (Hagerstown) 2007;8 (suppl 1):S42-S45.

World Cancer Research Fund/American Institute for Cancer Research: Food, Nutrition, Physical Activity, and the Prevention of Cancer: a Global Perspective. Washington, WCRF/AICR, 2007.

World Health Organization: Diet, Nutrition and the Prevention of Chronic Diseases. Geneva, WHO, 2003.

Xu J, Eilat-Adar S, Loria C, Goldbourt U, Howard BV, Fabsitz RR, Zephier EM, Mattil C, Lee ET: Dietary fat intake and risk of coronary heart disease: the Strong Heart Study. Am J Clin Nutr 2006;84:894-902.

-Yates AA: Using criteria to establish nutrient intake values (NIVs). Food Nutr Bull 2007;28: S38-S50.

Yokoyama M, Origasa H, Matsuzaki M, Matsuzawa Y, Saito Y, Ishikawa Y, Oikawa S, Sasaki J, Hishida $H$, Itakura $H$, Kita T, Kitabatake A, Nakaya N, Sakata T, Shimada K, Shirato K: Effects of eicosapentaenoic acid on major coronary events in hypercholesterolaemic patients (JELIS): a randomised open-label, blinded endpoint analysis. Lancet 2007;369:1090-1098. 